\title{
Diamond Genesis in the World's Largest Diamondiferous Eclogite, Part II: In-situ Isotope Study of Diamond and Mineral Inclusions
}

\author{
Yang Liu ${ }^{1}$, Lawrence A. Taylor ${ }^{1}$, Amit Basu Sarbadhikari ${ }^{1}$, John W. Valley ${ }^{2}$, Takayuki \\ Ushikubo $^{2}$, Michael J. Spicuzza ${ }^{2}$, Noriko Kita ${ }^{2}$, Alexander Stepanov ${ }^{3}$, Vladislav Shatsky ${ }^{3}$, \\ Nikolai V. Sobolev ${ }^{3}$ \\ ${ }^{1}$ Planetary Geosciences Institute, Dept. of Earth \& Planetary Sci., Univ. of Tennessee, Knoxville, TN 37996, USA \\ ${ }^{2}$ Dept. of Geology \& Geophysics, University of Wisconsin, 1215 W Dayton St. Madison WI 53706, USA; \\ ${ }^{3}$ Institute of Mineralogy \& Petrography, Russian Academy of Science, Novosibirsk 630090, Russia.
}

\begin{abstract}
Introduction
Diamonds and their mineral inclusions preserve important information about the physical and chemical conditions during diamond formation in Earth's mantle. Carbon isotopes in individual diamonds, in association with growth zones, have been used to study the crystallization of diamond (e.g. Bulanova, et al., 2002; Deines, 1980; Harte et al., 1999; Kirkley et al., 1991; Zedgenizov et al., 2004). Previous studies have been conducted on single diamonds or diamonds from different localities. In 2005, the world's largest diamondiferous eclogite $(8.8 \mathrm{~kg})$ was found at the Udachnaya kimberlite pipe. In this study, we report stable isotope compositions of diamonds extracted from a $1 / 2 \mathrm{~kg}$ portion (UDE 2005) of this eclogite, and major-element compositions of their inclusions.
\end{abstract}

\section{Methods}

Based on the X-ray tomography presented in Part I of our accompanying abstract on this unique eclogite (Liu et al., this volume), diamonds extracted at different locations inside the rock were selected. About 24 diamonds of $\sim 0.8-4 \mathrm{~mm}$ size were cut near $\{110\}$ to obtain the largest cross-sectional area possible. Some of these diamonds were cut to expose 2-3 inclusions simultaneously. These diamonds were then cleaned with distilled water and mounted in epoxy discs.

Cathodoluminescence (CL) images were collected using a CL microscope at the University of Tennessee. An electron beam with $\sim 5 \mathrm{keV}$ voltage and $0.25 \mathrm{~mA}$ current was used. Colored CL images of a small number of diamonds were collected. To minimize beam damage to the epoxy, grayscale CL images, which require shorter exposure times, were collected for the remaining diamonds.

In-situ carbon isotopes analyses of different CL zones in the cut diamonds were obtained using the CAMECA IMS-1280 at the University of Wisconsin. The diamonds were mounted in epoxy discs and coated with thin $\mathrm{Au}$ film. $\mathrm{A}^{133} \mathrm{Cs}^{+}$primary ion beam $(20 \mathrm{keV}$ total acceleration voltage) set at $0.7 \mathrm{nA} \quad(\sim 7 \mu \mathrm{m}$ in diameter). Secondary ions were extracted with $10 \mathrm{kV}$ and selected using a $40 \mathrm{eV}$ energy window. Two carbon isotopes $\left({ }^{12} \mathrm{C}^{+}\right.$and $\left.{ }^{13} \mathrm{C}^{+}\right)$were detected simultaneously with two Faraday cups. Analyses on UDE diamonds were bracketed with analyses on an inhouse standard (a Kelsey Lake diamond with $\delta^{13} \mathrm{C}$ of $5.9 \pm 0.2 \%$ o PDB (2SD, $n=4)$ to correct for instrumental bias. The spot-to-spot reproducibility of $\delta^{13} \mathrm{C}$ was typically $0.5 \%$ o (2SD).

Major-element compositions of mineral inclusions were analyzed using the CAMECA SX50 electron microprobe at the University of Tennessee. Analytical conditions include an acceleration voltage of $20 \mathrm{keV}$, a beam current of $10 \mathrm{nA}$, and a beam size of $2 \mu \mathrm{m}$.

\section{Results}

\section{CL zonings}

Most diamonds have the typical blue cathodeluminescence. The brightness of the color is associated with the abundance of defects and has been found to associate with nitrogen abundance (e.g., Harte et al., 1999). A yellow-green cathodoluminescence color was seen in a few diamonds (e.g. D-64 in Fig. 1). A similar CL color was reported for Kaapvaal diamonds by Harte et al. (1999) and was attributed to very low nitrogen contents $(<50 \mathrm{ppm})$.

All diamonds have a non-luminescent (or dark blue) rim, indicative of fibrous growth (Fig. 1). Small diamonds $(\leq 1 \mathrm{~mm})$ possess skeletal morphologies and are weakly luminescent and weakly zoned (e.g. D-35 and D-81 in Fig. 1). Diamonds $>1 \mathrm{~mm}$ generally show alternating bright- and dark-blue zones in the interior. A few large diamonds (3-4 mm) contain cores with jagged boundaries (D-31 D-73, D-5b1, and D-38 in Fig. 1), demonstrating resorption features and multiple growth episodes.

\section{Carbon isotopes}

The total range of $\delta^{13} \mathrm{C}$ observed in 126 analyses of the 24 diamonds is -9.0 to $-2.2 \%$ with most of the data in the -5 to $-6 \%$ range (Fig. 2). Multiple analyses on the 
standard diamond yield a precision of $0.5 \%$ for 2 standard deviations of the SIMS data.

There is no clear correlation between CL intensity and $\delta^{13} \mathrm{C}$, concurring with the result of Harte et al. (1999). The $\delta^{13} \mathrm{C}$ values of these rims ( -5 to $-6 \%$ ) are similar to each other and to the typical mantle value (Kirkley et al., 1991), suggesting that they grew from the same fluid at the late stage. The $\delta^{13} \mathrm{C}$ values of different $\mathrm{CL}$ zones inside most diamonds are similar to the rim (vary by 1-2\%) and to the mantle value (Figs. 1 and 2 ). These similar values suggest that they also grew from a similar fluid.

Three diamonds contain $\delta^{13} \mathrm{C}$ values significantly different from the average value $(-5.5 \%)$ outside the statistical range of the analyses. Diamond D-31 contains a dark, irregular CL "core" with $\delta^{13} \mathrm{C}$ values of $-9.0 \%$, whereas diamond D-73 shows a jagged core with $\delta^{13} \mathrm{C}$ values of $-3.3 \%$ (Figure 1). The intermediate zones of these two diamonds have similar $\delta^{13} \mathrm{C}$ values $(\sim-5.5 \%)$. A small skeletal, nonluminescent diamond (D-35) contains a core enriched in ${ }^{13} \mathrm{C}\left(\delta^{13} \mathrm{C}=-2.2 \%\right)$.

Diamonds formed by Rayleigh fractionation from a vapor phase can have increasingly heavier (for $\mathrm{CO}_{2}$ vapor) or lighter (for $\mathrm{CH}_{4}$ vapor) carbon isotopic compositions from core to rim (Deines, 1980; Kirkley et al., 1991). However, the reversed trends of $\delta^{13} \mathrm{C}$ values between D-73 and D-31 suggest that these diamonds come from different sources, and then grew in similar fluid(s). The non-luminescent nature of small diamond D-35 and its decreasing $\delta^{13} \mathrm{C}$ values from core to rim could be a feature of fast growth with $\mathrm{CH}_{4}$ degassing. Overall, carbon isotopic data suggest
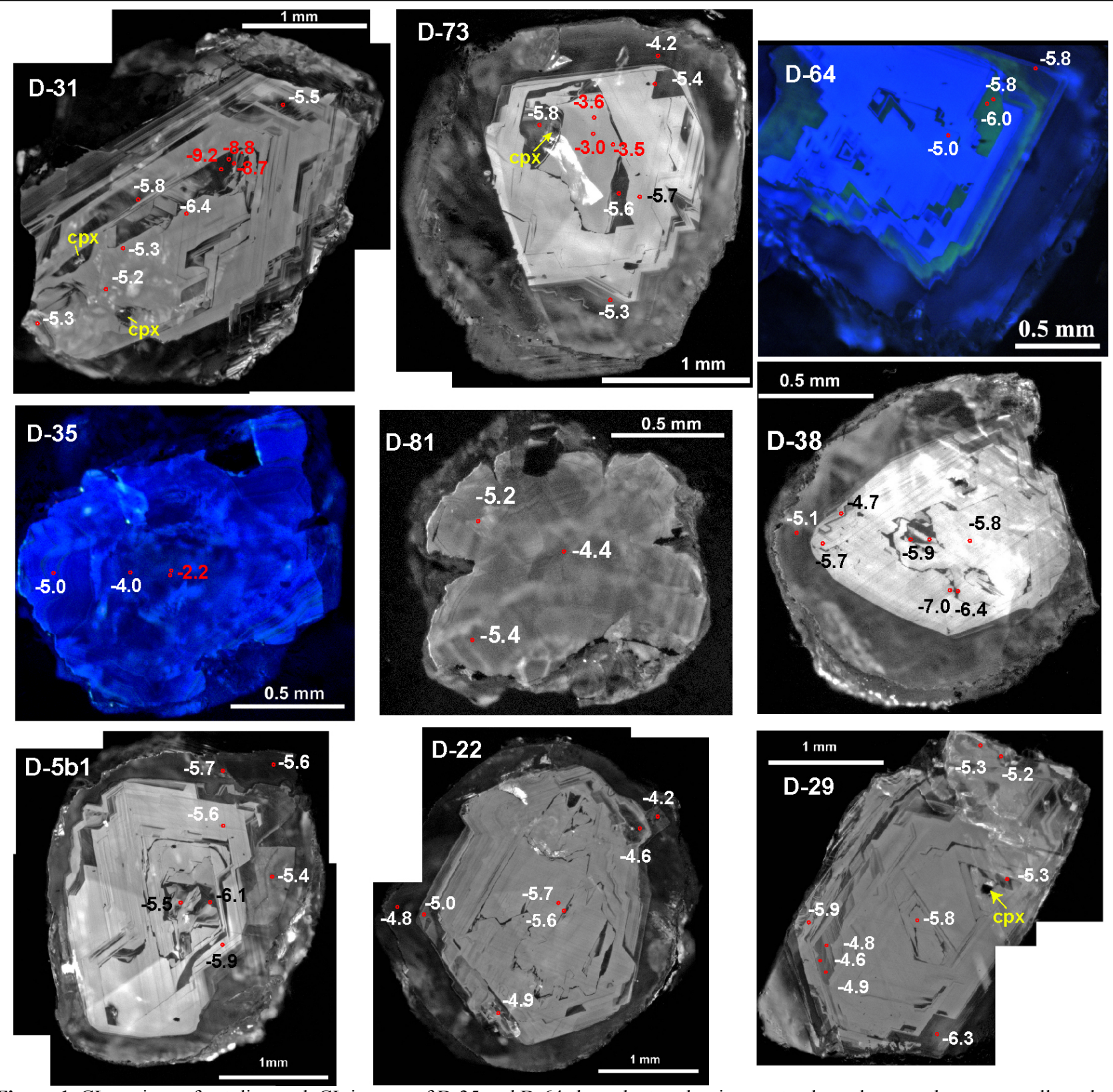

Figure 1. CL zonings of cut diamond. CL images of D-35 and D-64 show the true luminescent color, whereas others were collected on a grayscale. The carbon isotopes and the ion-probe analytical spots were marked by red circles. Clinopyroxene inclusions were labeled in yellow. Note the green color of a luminescent zone in D-64. 
diamonds in this xenolith grew in an open system and were in contact with different fluids during their growth.

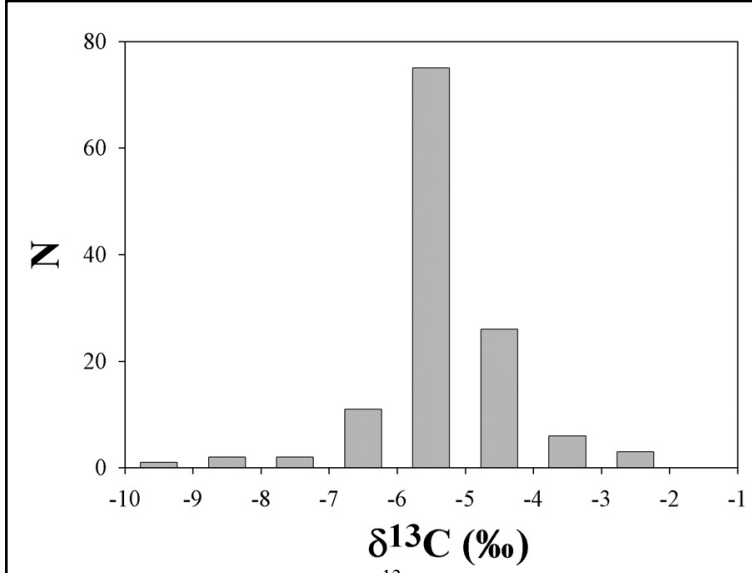

Figure 2. Histogram of all $\delta^{13} \mathrm{C}$ data of diamonds.

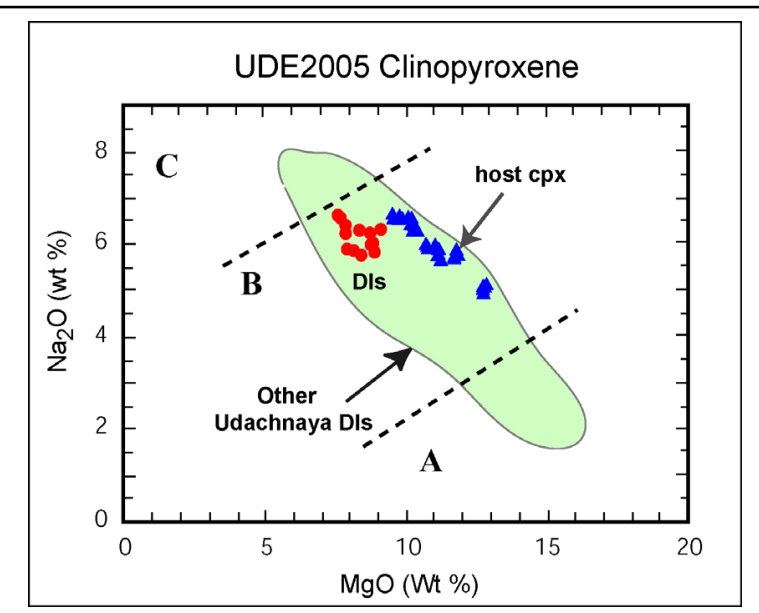

Figure 3. Composition of clinopyroxene inclusions (red circles) and hosts (blue triangles) in UDE 2005. The green field plots other clinopyroxene inclusions in diamonds found in other eclogite xenoliths from Udachnaya (Taylor and Anand, 2004).

\section{Composition of inclusions}

Silicate inclusions in extracted diamonds are all omphacites (Fig. 3), some of which show a spongy texture (diopside-rich cpx and interstitial K-rich glass or feldspar) with no apparent evidence for open system behavior, similar to Taylor et al. (2000). Theses pristine clinopyroxenes are all Group B pyroxenes (Taylor and Neal, 1989), similar to clinopyroxene inclusions in diamonds from other eclogitic xenoliths from Udachnaya (Taylor and Anand, 2004) (Fig. 3). These clinopyroxene inclusions contain less $\mathrm{Na}_{2} \mathrm{O}$, $\mathrm{MgO}$, but slightly higher $\mathrm{K}_{2} \mathrm{O}(\sim 0.1$ wt.\%) than host omphacites, implying that inclusions were trapped at higher pressures and/or the host rock has reequilibrated to lower P-T.

\section{Concluding Remarks}

Confirming observations from HRCXT (tomography) and dissection of this huge eclogite (Liu et al., this volume), CL zonings in diamond, carbon isotope ratios of diamonds, and mineral inclusion compositions, suggest that diamonds in this sample, the world's largest diamondiferous eclogite, were formed by multiple metasomatic events. These results add strong support to similar conclusions from other diamondiferous eclogite studies that diamonds were seldom if ever formed synchronously with the host eclogite (Taylor and Anand, 2004).

\section{References:}

Bulanova, G. P., Pearson, D. G., Hauri, E. H., Griffin, B. J., 2002. Carbon and nitrogen isotope systematics within a sector-growth diamond from the Mir kimberlite, Yakutia. Chemical Geology, 188, 105-123.

Deines P. (1980) The carbon isotopic composition of diamonds - relationship to diamond shape, color, occurrence and vapor composition. Geochimica et Cosmochimica Acta, 44, 943961.

Harte, B., Fitzsimons, I. C. W., Harris, J. W., Otter, M. L. (1999) Carbon isotope ratios and nitrogen abundances in relation to cathodoluminescence characteristics for some diamonds from the Kaapvaal Province, S-Africa. Mineralogical Magazine, 63, 829-856.

Kirkley, M. B., Gurney, J. J., Otter, M. L., Hill, S. J., Daniels, L. R., 1991. The application of C isotope measurements to the identification of the sources of $\mathrm{C}$ in diamonds - a review. Applied Geochemistry, 6, 477-494.

Liu Y., Taylor, L.A., Sarbadhikari, A.B., Ketchum, R., Carlson, W., Stepanov, A., Shatsky, V., Sobolev, N.V., 2008. Diamond genesis in the world's largest diamondiferous eclogite, part I: $\mathrm{X}$-ray tomography and xenolith dissection. This vloume.

Taylor, L. A., Anand, M., 2004. Diamonds: time capsules from the Siberian Mantle. Chemie Der Erde-Geochemistry, 64, 1-74.

Taylor, L. A., Neal, C. R., 1989. Eclogites with oceanic crustal and mantle signatures from the Bellsbank kimberlite, South-Africa .1. Mineralogy, petrography, and whole rock chemistry. Journal of Geology 97, 551-567.

Taylor, L.A., Keller, R.A., Snyder, G.A., Wang, W., Carlson, W.D., Hauri, E.H., McCandless, T., Kim, K.-R., Sobolev, N.V., Bezborodov, S.M., 2000. Diamonds and their mineral inclusions and what they tell us: a detailed "pull-apart" of a diamondiferous eclogite. International Geology Review, 42, No. 12, 959-983.

Zedgenizov, D. A., Harte, B., 2004. Microscale variations of delta $\mathrm{C}-13$ and $\mathrm{N}$ content within a natural diamond with mixed-habit growth. Chemical Geology, 205, 169-175. 